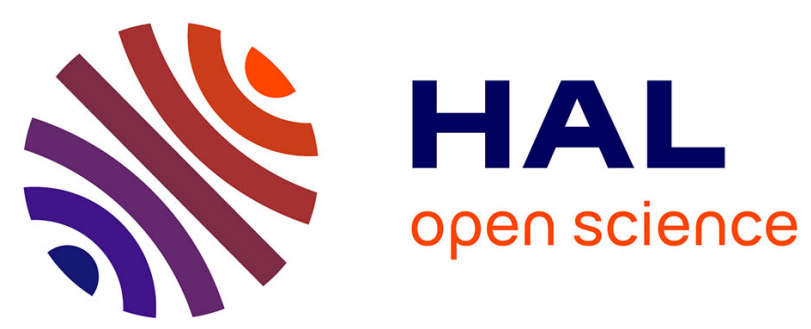

\title{
XAFS Studies of Self-Aligned Platinum Silicide Thin Films at the Pt M3,2 Edge and the Si K-Edge
}

\author{
S. Naftel, A. Bzowski, T. Sham, D.-X. Xu, S. Das
}

\section{To cite this version:}

S. Naftel, A. Bzowski, T. Sham, D.-X. Xu, S. Das. XAFS Studies of Self-Aligned Platinum Silicide Thin Films at the Pt M3,2 Edge and the Si K-Edge. Journal de Physique IV Proceedings, 1997, 7 (C2), pp.C2-1131-C2-1132. 10.1051/jp4:19972158 . jpa-00255221

\section{HAL Id: jpa-00255221 https://hal.science/jpa-00255221}

Submitted on 1 Jan 1997

HAL is a multi-disciplinary open access archive for the deposit and dissemination of scientific research documents, whether they are published or not. The documents may come from teaching and research institutions in France or abroad, or from public or private research centers.
L'archive ouverte pluridisciplinaire HAL, est destinée au dépôt et à la diffusion de documents scientifiques de niveau recherche, publiés ou non, émanant des établissements d'enseignement et de recherche français ou étrangers, des laboratoires publics ou privés. 


\title{
XAFS Studies of Self-Aligned Platinum Silicide Thin Films at the Pt $\mathbf{M}_{3,2}$ Edge and the Si K-Edge
}

\author{
S.J. Naftel, A. Bzowski, T.K. Sham, D.-X. Xu* and S.R. Das* \\ Department of Chemistry, University of Western Ontario, London, N6A 5B7, Canada \\ * National Research Council of Canada, Institute for Microstructural Science, Ottawa, KIA OR6, Canada
}

\begin{abstract}
Abstact Pt-Si thin films with the thickiness of several hundred $\AA$ prepared on $n$-type Si(I00) by UHV sputter-deposition procedures and subsequent annealing have been studied with $X$-rav absorption fine structure spectroscopy at the $P t M_{3.2}$ edge and the Si K-edge. It is found that. under favourable conditions, single phase PtSi films can be obtained. These films exhibit the same XAFS characteristics as those of bulk samples. The $M_{3,2}$ edge exhibits XANES features very similar to those of the Pt $L_{3.2}$ edge obtained from the samples. The analysis of the $\mathrm{Pt} \mathrm{M}_{3.2}$ edge whiteline and the Si K-edge results show significant charge redistribution at both $\mathrm{Pt}$ and $\mathrm{Si}$ sites upon silicidation.
\end{abstract}

\section{INTRODUCTION}

Transition metal silicides are used in the microelectronics industry as schottky barrier clamps between the base and collector for fast switching operations and for low resistance contacts to source drain and gate [1]. As the size of devices shrinks it is of paramount importance to understand the behaviour of thin films of transition metal silicides with micrometer dimensions. In this study we look at the electronic behaviour of PtSi films using XANES.

\section{EXPERIMENTAL}

The PtSi samples were created by magnetron sputter depositing layers of Pt on $\mathrm{Si}(100)$ crystals followed by RTA (rapid thermal annealing) procedures performed ex situ under $\mathrm{N}_{2}$ atmosphere to form the silicides as described elsewhere [2].

Both $\mathrm{Pt} \mathrm{M}_{3,2}$ edges and $\mathrm{Si} \mathrm{K}$-edge spectra were taken under similar experimental conditions on the Double Crystal Monochrometer beamline in the Canadian Synchrotron Radiation Facility at SRC, University of Wisconsin-Madison. InSb(111) crystals were used as the monochrometer. The spectra were collected in TEY mode (specimen current) at room temperature.

$\mathrm{Pt}_{3,2}$ edge XANES were recorded on the X-I lA beamline of the National Synchrotron Light Source (NSLS) at Brookhaven National Lab using a He amplified TEY detector.

\section{RESULTS AND DISCUSSION}

Figures 1 and 2 show, respectively, the $P t M_{3}$ and $M_{2}$ edges of $P t$ metal and some representative $P t S i$ films normalized to the edge jump. It is clear that after annealing (silicidation) the area of both whitelines increases relative to the $\mathrm{Pt}$ sample. The increase in area is related to the $d$ hole counts and indicates that $\mathrm{Pt}$ loses $d$-charge in the formation of $\mathrm{PtSi}$. It is interesting to note that the area of the $M_{2}$ whiteline increases more rapidly than the area of the $M_{3}$ whiteline, this would suggest that the loss of charge is preferentially from the $d_{3 / 2}$ level.

We have recently compared the $L_{3,2}$ and $M_{3,2}$ edge XANES of the $5 d$ elements and shown that both can be used as a measure of the occupancy of the $d$ states in the $5 d$ transition metals $[3,4]$. If we compare the PtSi films spectra to a bulk PtSi spectra from literature [5] we see that the spectra compare favourably indicating that the bulk of the films are PtSi regardless of the annealing time. The unannealed sample is almost identical to the Pt metal spectrum indicating that little silicidation takes place without annealing.

To calculate the areas under the whitelines we use the Au $M_{2}$ XANES spectra, taken under similar conditions, normalized and calibrated in the same way as the other spectra and subtract it as a background [3]. The area under the difference curve is the area of the whiteline. This is reasonable as $A u$ has no $d$ holes and thus the $M_{2}$ spectrum exhibits no whiteline and is almost an arctan edge. It is estimated that the use of the $A u M_{2}$ edge and inaccuracies in the alignment of the spectra lead to an error of 5 to $10 \%$ in the calculated areas $[4]$. The areas can easily be related to the $5 d$ hole count at the Pt site through the equations $[6]$

$$
A_{2}=C_{0} N_{0} E_{2}\left(R_{d}^{3 p / 1 / 2}\right)^{2}\left(1 / 3 h_{3 / 2}\right)
$$




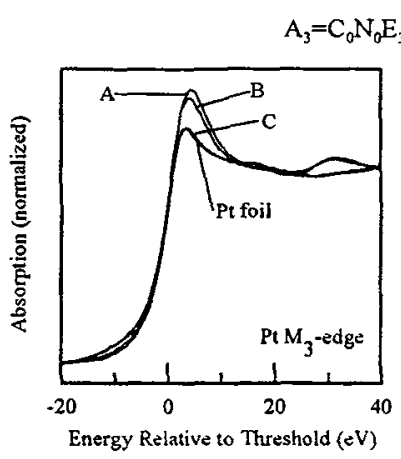

Fig. 1: $\mathrm{Pt} \mathrm{M}_{3}$-edge XANES of $\mathrm{Pt}$ foil and $\mathrm{Pt}$ films: A) annealed $400^{\circ} \mathrm{C}, 475^{\circ} \mathrm{C} .555^{\circ} \mathrm{C} / 30 \mathrm{sec},(x 116)$, B) annealed $400^{\circ} \mathrm{C} / 30$ sec. $\left.(x 115), C\right)$ unannealed $(x 150 t)$.
(2)

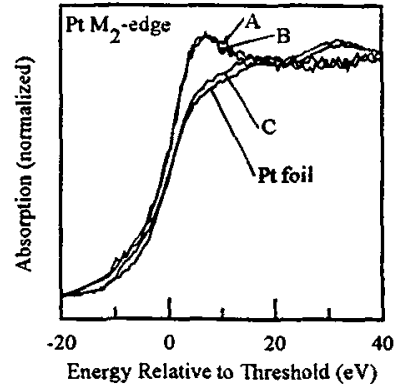

Fig. 2: $\mathrm{Pt} \mathrm{M}_{2}$-edge XANES of $\mathrm{Pt}$ foil and $\mathrm{Pt}$ films; A) annealed $400^{\circ} \mathrm{C}, 475^{\circ} \mathrm{C}, 555^{\circ} \mathrm{C} / 30$ sec. $\left.(x 116), B\right)$ annealed $\left.400^{\circ} \mathrm{C} / 30 \mathrm{sec} .(\mathrm{x} \mid 15), \mathrm{C}\right)$ unannealed $(\mathrm{x} 150 \mathrm{f})$.

Using eqs. (1) and (2) we can calculate the $h_{3 / 2}$ and $h_{5 / 2}$ hole counts of the silicides in reference to the theoretical $h_{3 / 2}$ and $h_{5 / 2}$ hole counts of $\mathrm{Pt}$ metal [6]. The resuits are presented in table 1. The net result is that the ratio of holes $h_{5 / 2} / h_{3 / 2}$ decreases towards it's statistical value $(1.5)$ as $\mathrm{Pt}$ loses $d$-charge during the formation of $\mathrm{PtSi}$. Areas calculated from the $\mathrm{Pt} \mathrm{L}_{3,2}$ edges follow the same trend.

Figure 3 shows the Si K-edge XANES of Si(100) and some PtSi thin films. The large peak at $\sim 1847 \mathrm{eV}$ is attributed to a surface oxide which complicates the analysis of the $\mathrm{Si} \mathrm{K}$-edge spectra. However, since $\mathrm{SiO}_{2}$ has a flat pre-edge and the spike is $>7 \mathrm{eV}$ above the $\mathrm{Si}$ threshold, it has little effect on the XANES structure for regions $<7 \mathrm{eV}$ above the threshold. Furthermore the oxide peak can be removed by subtracting the $\mathrm{SiO}_{2}$ contribution from the PtSi spectrum. In any case it is clear from figure 3 that $\mathrm{Si}$, in the PtSi films, has a more intense whiteline and thus loses $p$-charge. This is in contrast to the $3 d$ metal silicides study recently done by Weijs et al. [7]. The implication of Si losing $p$-charge is that it gains $s$-charge to maintain efectroneutrality locally.

Table 1: Whiteline areas and $d$ hole counts derived from the $P t M_{3,2}$ edges. (the uncertainty in the areas and hole counts is not greater than $5 \%$ and $7 \%$ )

\begin{tabular}{c||c|c|c|c|c} 
Sample & $\begin{array}{c}\mathrm{A}_{2} \\
\text { (eV unity abs.) }\end{array}$ & $\begin{array}{c}\mathrm{A}_{3} \\
\text { (eV unity abs.) }\end{array}$ & $\mathrm{h}_{3 / 2}$ & $\mathrm{~h}_{5 / 2}$ & $\mathrm{~h}_{\mathrm{s} / 2} \mathrm{~h}_{3 / 2}$ \\
\hline \hline Pt foil & 2.54 & 7.16 & 0.344 & 1.0 & 2.90 \\
$\times 150 \mathrm{f}$ & 2.56 & 7.10 & 0.346 & 0.992 & 2.87 \\
$\times 115$ & 5.27 & 7.89 & 0.712 & 1.05 & 1.47 \\
$\times 116$ & 5.32 & 8.03 & 0.719 & 1.07 & 1.48
\end{tabular}

\section{SUMMARY}

We have reported the Pt $\mathrm{M}_{3,2}$ and Si K-edge XANES tor a series of PtSi tilms. The as-deposited Pt layers do not form silicides. When annealed a layer of PtSi is formed. Analysis of the whiteline areas showed significant charge redistribution on silicidation with the Si site losing $p$-charge and the Pt site losing $d$-charge such that the $d$ hole count ratio moves towards its statistically expected value.

\section{References}

(1) See for example, Appl. Surt. Sci. 53 (1991); the entire volume deais with metal silicides and their applications.

[2] Das S. R., Xu D.-X., Phillips J., McCaftrey J.. LeBrun L., and Naem A., MRS Symp. Proc.. 318 (1994) $129-134$.

[3] Sham T. K., Naftel S. J., Coulthard I.. This conference.

[4] Sham T. K., Naftel S. J., Coulthard I., J. Appl. Phy's., 79 (1996) 7134-7138.

[5] Rossi G., Surf. Sci. Rep., 7 (1987) 1-101.

[6] Mantheiss L. F., Diezz R. E., Phys. Rev. B. 22 (1980) 1663-1673.

[7] Weijs P. J. W., Czyżyk M. T., van Acker J. F., Speier W., Goedkoop J. B.. van Leuken H., Hendrix H. J. M., de Groot R. A., van der Laan G., Buschow K. H. S., Wiech G.. Fuggle J. C., Phys. Rev. B. +1 (1990) 11899-11910. 